\title{
The Comparison between Chinese and Western Well-Being
}

\author{
Defeng Yang, Han Zhou \\ School of management, Jinan University, Guangzhou, Guangdong \\ Email: angelazhou0227@163.com
}

How to cite this paper: Yang, D.F. and Zhou, H. (2017) The Comparison between Chinese and Western Well-Being. Open Journal of Social Sciences, 5, 181-188 https://doi.org/10.4236/jss.2017.511013

Received: October 30, 2017

Accepted: November 27, 2017

Published: November 30, 2017

Copyright $\odot 2017$ by authors and Scientific Research Publishing Inc. This work is licensed under the Creative Commons Attribution International License (CC BY 4.0).

http://creativecommons.org/licenses/by/4.0/

\begin{abstract}
The marked variation between China and other nations in well-being may be due to the influence of national culture [1]. Considering the dramatically different cultural background between China and western societies, to investigate comprehensively Chinese well-being is important. In this literature review, firstly, we will introduce the understanding of well-being for Chinese people. Secondly, we introduce the concept of beauty, which is an important component of Chinese well-being be neglected by western scholars. Thirdly, the differences between Chinese and western well-being are presented.
\end{abstract}

\section{Keywords}

Well-Being, Beauty, Chinese Culture, Culture Comparison

\section{Well-Being in China}

Chinese researchers normally view well-being as subjective well-being based on traditional culture and values. The meaning of well-being in China is more like "happiness" or "subjective well-being" in related English literatures [2]. This is because subjective Well-Being emphasises an experience which involves evaluation by individuals of their quality of life according to the standard they set for themselves. Democritus is one of the first Geek philosophers suggesting that happiness is only subjective, thus it "does not depend solely on good fortune or indeed on any external contingencies, but also, and even to a greater extent, on a man's cast of mind". In the field of psychology, hedonism tends to be interpreted holistically and with reference to body, mind, and society [3]. We summarize Chinese researchers' achievements, basically based in the view of subjective well-being, and explore the correlations between Chinese welling and psychological wellbeing, which is a new area to be found. 
Chinese place great emphasis on harmonious, interpersonal relationships for their subject well-being. These characteristics of subjective well-Being have been influenced largely by the culture's traditional view of happiness. Traditionally in Chinese culture, well-being isn't defined specifically but expressed using the word "Le" (happiness), "Le" is a psychological experience which is based on an empirical, inner experience of feelings.

"Le" is a word carrying several different meanings. Firstly, it expresses the feeling of joy, happiness, optimism and well-being. Secondly, it can describe the melody of music, the sound in harmony. Moreover, which is not well known by people, the original meaning of "Le" in ancient times, is basically the well-being gained when recovering from illness and when finally healing. Gradually, "Le" evolved into a general concept which not only expresses well-being from owning a healthy body, but extend to the meaning of well-being derived from material and spiritual wealth.

The multi-cultural nature of ancient Chinese society has helped to form the characteristics associated with the Chinese view of happiness. We will go deep inside Chinese well-being based on three important philosophical schools of thought in China, Confucianism, Taoism and Buddhism.

\subsection{Confucianism}

Confucius believes we can achieve happiness along many different ways in life. It is categorized into two levels: the first level is where happiness is derived from being satisfied with basic needs in real life, and the second where rational happiness comes from being kind to others and contributing to society at large (feeling of social value) [4].

The first level is the satisfaction of basic needs in real life. The status at which individuals should be safe and comfortable, regardless of the threat of illness and death, that is called "Being without anxiety or fear". The basic psychological experience not only consists of "no anxiety or fear" for an individual but also caring about the safety and soundness for one's family and friends. The first level mostly expresses the folk idea of well-being: the theory of "Fu". Ordinary Chinese folk take well-being as having abundant material wealth, health, moral character, a peaceful life and the reduction in the anxiety of death [4].

Another way to happiness in this first level is the happiness of temperament or experience. That basically means the joyful experience that music brings to the listener. Confucius didn't deny the pleasure of sensory experiences, but emphasises moderation, and speaks against indulgence in pleasure. What's more, the man with virtue should share the pleasure with others, leading this happiness to a higher level, which is happiness of the rational. As it is said "the superior man gets improvement of self-cultivation from music, the mean men just get satisfied from their own desire".

The rational happiness is based on the core concept in Confucian "ren", the virtue. The master explains the happiness of Hûi independent of his poverty. $\mathrm{He}$ said, "Admirable indeed was the virtue of Hûi! With a single bamboo dish of 
rice, a single gourd dish of drink, and living in his mean narrow lane, while others could not have endured the distress, he did not allow his joy to be affected by it." That means only true virtue adapts man to the varied conditions of life. The Master also said, "Those who are without virtue cannot abide long either in a condition of poverty and hardship, or in a condition of enjoyment", "the virtuous are free from anxiety", both meaning that happiness is derived from virtue. Later generations develop this explanation of happiness further. "Be the first to worry about the troubles across the land, the last to enjoy universal happiness." Is a line from a poem from the Song dynasty and actually represents how the intellectual class in ancient China thought about achieving their happiness. The Confucian way to achieve happiness can develop from perceptual to rational, from individual to collective. In other words, the happiness of individuals is built on being concerned about the world.

In sum, "Le" can be categorised at two different levels. One is satisfying basic demands. At this level, happiness can continue to be divided into two parts, being satisfied with material and emotion needs and enjoying happiness of temperament. Secondly, Confucius believes happiness is both a temporal, objective status in life, and an internal, subjective, experiential, or psychological experience [5]. The rational happiness can neutralize the practical concerns derived from lacking material stuff or facing difficulties. This reveals another characteristic of Confucius' happiness: well-being is somehow based on external objective things, but even without these external safeguards, one can also achieve well-being as long as one has virtue inside. Confucians believe well-being is derived from the process of seeking virtue. Knowledge seeking, being kind to others, or creating harmony in a group can be useful [2]. The happiness of family and clan is more important than the individual's happiness. Confucianism is an idealistic one that advocates rationality, involvement in society and taking pleasure in life [6]. It manifests itself in the idea that the person who practices benevolence is free from anxiety, takes a moral attitude to the world, feels concern about the state of the country and its people, endures poverty patiently and remains calm in the face of adversity. The researchers all agree that Confucians' happiness is spiritual, moral and self-determined, and that it is a psychological and mental state.

\subsection{Taoism}

Taoism's view of happiness requires people to look beyond reality for happiness and suggests that happiness could be acquired from appreciating the beauty of nature and life. Taoism also suggests that happiness and unhappiness were related. They are dependent on each other and can be transferred [4]. Compared to Confucian, Taoism takes less care of external reality and people should not rely on the material world for happiness.

The essence of "Le" for Taoism: forget about the reality, the material, the live or death as well as ourselves, achieve the absolute freedom and the "Dao" (the principles of universe) [6]. Taoism's happiness is more like a concept beyond 
happiness. It emphasises there is no difference between happiness and worries. One of the spiritual core of Taoism is "Unity of Man and Nature". Taoism stresses man's oneness with nature and the need to adapt to circumstances as they arise. It advocates the pursuit of a state of conformity with nature and an abstention from reckless behaviour, so as to arrive at a point where "extreme pleasure is no pleasure". Here is an extreme example that happened to Zhuangzi, when Zhuangzi's wife died, he sang instead of cried. In the philosophy of Taoism, they view everything as approaching well-being. It seeks detachment to achieve a status beyond happiness but they don't deny or avoid the profane perceptual happiness. Zhuangzi didn't take death as a rescue or relief so it appears to have perceptual realistic freedom and happiness. So people always practice the culture of optimism [7].

A unique concept for understand Taoism's well-being is such a dialectical belief that "every cloud has a silver lining". As it is said in "Tao Te Ching": Luck and Misfortune comes in turn, it means how one treats fortune and misfortune influences the subjective feeling. When something good happens, don't be overwhelmed. When something bad happens, stay calm. Achieving a state of no worries, no happiness, is the true well-being. No happiness here means no happiness from the secular world. Taoism's view of happiness is to free people from the desires man can have [2]. Don't be the slave of desire, follow the natural rhythms, accept destiny and finally achieve well-being. Laozi emphasises to decrease desire and don't pursue external things. Zhuangzi didn't negate all the desires of humans except those related to fortune and fame. They all define human's desire concentrated on the respect of life, following the "Le" in nature, but physical desire [8].

Cognition can decide emotional states. How people treat fortune and misfortune influences the attitude to pursue well-being for Chinese. They become calmer and always have an optimistic attitude for life. Chinese people don't value well-being so much as westerners. Well-being may not be the most important thing for Chinese.

Subjective well-being in western cultures comprises three main components: affective dimensions including positive affect, absence of negative affect, and satisfaction. Based on objective list theories, certain things are good or bad for us, whether or not we want to have the good things, or to avoid the bad things. Although westerners and Chinese both observe that unpleasant conditions happen inevitably in life, they treat negative affect in a totally different way. Westerners try to reduce the negative affect which influences well-being in an opposite way. Chinese are actually calmer and are capable of transfering negative affect into positive affect.

As the two most influential ideologies, comparison between Taoisma and Confucianism is important. Although both of them emphasise optimistic emotional experiences, Confucians proceed from perceptual and rational, and advocate for people to go into society positively, and show more characteristic of ethics [6]. While, Taoism teaches the other optimism about escaping from society, 
the ideology meaning is beyond realistic. Regarding their content, Confucianism values the happiness derived from morality, but Taoism pays more attention on the happiness of freedom of spirit. For ways of achieving happiness, Taoism against Confucian that believe the way to well-being is a process people should put effort to achieve eudaimonia. Taoism interprets well-being as freeing people from human desire, by letting things take their own course (do nothing), facing life with a peaceful mind [2].

\subsection{The Buddhist}

The Buddhist view was that everything in life was empty and suffering for humans apart from entering nirvana and that helping other people to get into nirvana would help them to achieve Subjective Well-Being [4]. Buddhism teaches a way of life aimed at turning suffering into happiness, doing good in order to accumulate merit and devoting oneself to charitable works [6].

The Buddhists believe well-being can only be achieved after nirvana, similar to hen entering the western paradise, it promises people to get rid of the suffering in the real world. People can achieve eternal well-being by monasticism, meditative mindfulness, alms giving and eliminating all desires [2]. The "Heart Sutra" mentions that well-being is free of desire, attaches importance to altruistic behaviour, and not to be competitive with others, and finally to pursue a peaceful harmonic mind.

The Buddhist is a religion for small number of Chinese. Therefore the well-being of the Buddhist has limited influence on Chinese.

\section{The Concept of Beauty}

Beauty is a kind of emotional experience [9], and a very important concept for Chinese. Both Confucians and Taoism take it as a serious concept which can influence well-being. Firstly, beauty is a satisfaction of sensual pleasure. Similar to hedonism in psychology, it tends to be interpreted holistically and with reference to body, mind, and society [3]. And the feeling of beauty is extremely subjective. For Chinese, no matter whether appreciating the beauty from art or nature, the object will influence people and satisfy the needs and ideals of beauty. Many positive things are related to beauty, even secular ones; Chinese can appreciate it beyond reality and enter into an aesthetic realm [4]. How Chinese appreciate beauty is far more than just sensual pleasure but includes the both rationality and spirit [9].

The Confucians' concept of beauty is particular about pursuing emotional needs besides caring about reality. The researcher goes deep into a consistent word "Le", put out the theory of the stratification of Confucian's aesthetic realm, such as enjoying the joy of music and landscape, enjoying the joy of learning and making friends, enjoying the joy of Yan Hui's and Zeng Dian's [10]. The ancient intellectuals love to abandon themselves to nature. They appreciate the harmony of nature, give themselves over to the process, go into a peaceful situation after a strong emotion brought by the beauty of nature, furthermore achieve well-being. 
Taoism seeks to get rid of the pleasure of sensual pleasure, and views everything from the aspect of art. They believe when one can understand "Dao", and actually achieve both well-being and "ultimate beauty". The subjective view of the world is metaphysical. The pure pleasure of sensual or physiological is a kind of suffering in the aesthetic realm [10].

Secondly, the Confucian concept of beauty differs from the Greek concept. In Greece, truth, goodness, and beauty are three separate concepts in three fields: truth in the scientific field, goodness in the ethical field, and beauty in the field of arts. In China, these three concepts are not separate concepts in three fields. They are so intimately tied together as to seem inseparable [11]. The beautiful, to Mencius, is also the true, "Whatever is full is beautiful." The beautiful, to Confucius, is also the good. "A neighbourhood with a ren man in it, he said, is a beautiful neighbourhood." He often used the word "beautiful" as a synonym for "virtuous". In fact, among all the philosophers in the world, Confucius was probably the first one who applied the concept of beauty to morals and art [11].

In sum, appreciating beauty can lead people to well-being. What's more for Taoism, well-being is somehow equal to beauty. The aesthetic realm is an emotional happiness combined with rationality and desire [8].

\section{The Differences between Chinese and Western Well-Being}

The orientation of well-being is essentially determined by the culture. When it comes to cross-cultural research, scholars often make comparison based on Hofstede's cultural dimensions theory, especially divide them into Individualoriented and socially oriented culture.

As far as I am concerned, it will be more valuable to find out the commonality and differences based one the two types of well-being. In subjective well-being, the differences are from the view of self-construal [12]. They find significant differences in origin, meaning, connection and time, which are the four aspects of well-being. Clearly, well-being for Chinese has four characteristics: harmony, worthiness, sociability and futurity. Traditional Chinese culture and determine that it is unique in three characteristics: first, personal emotion is not the key point in subject well-being but rather interpersonal relationships and the feelings of social value; second, Subjective Well-Being of the individual is not a single feeling and is always connected to a moral sense and a sense of beauty; third, Chinese traditional culture encourages people to pursue rational happiness, which transcends happiness and Subjective Well-Being in reality [4].

In comparison to Psychological Well-being, although few researchers relate Chinese traditional well-being to Psychological Well-being, Confucian's well-being shares some similarities with Psychological Well-being. Aristotle meant by "well-being" that humans can attain eudaimonia by fulfilling their own potential. Eudaimonia is associated with possession of what is most valued [13]. Another Aristotelian concept, "virtue", can help clarify what should be valued the most. An edudaimonic approach is objective in the sense that it views some human 
activities as valuable and connects human beings to engaging with those valuable activities. The researcher indicate one should live in accordance with virtue, which is thought of by Aristotle as characterized by what is simultaneously best and moderate; for neither too much pleasure nor too little of it is desirable, which is similar to what Confucians advocate [14]. Confucians also believe that basic needs should be satisfied; moreover, in Chinese folk happiness, satisfaction is well accepted. Confucians also value virtue, for the intellectual class they take virtue as an important principle. The difference in the understanding of virtue is, Chinese evaluate it more as social-oriented. Besides achieving one's individual potential, they care more about how to contribute to others, the country as well as the society.

Well-being in China is more like a consistent status from the very beginning of the activities rather than a feeling after we actually achieve the goal. In Deci's three experimental studied used SDT and found that success in an activity while feeling autonomous leads to both happiness (hedonically defined in their research as "high pleasantness per se" and vitality. They emphasise success in the activity under pressure leads to happiness based on the assumption of causality [15]. While in China, the master comments on the different stages of attainment when we learn knowledge. "They who know the truth are not equal to those who love it, and they who love it are not equal to those who delight in it." These three different psychological levels are combined, while all of them point to the ideal state, which is "Le", meaning the highest level of happiness. Confucius emphasises, when we participate in some valuable activities, if we enjoy the whole progress process?, whether or not you finally achieve the goal, you have already known well-being.

In my opinion, Westerners prefer the taxonomic view on the issue of well-being. They love to view things in terms of body and soul; they are two separate concepts. They also divide well-being into two separate parts. Although today, researchers are trying to combine these two concepts but still researches distinguish the two domains, while Chinese like to think about things holistic. Different from body and soul, Chinese prefer to combine them together, value more about "heart" or "mind" in English.

\section{Conclusion}

Traditional Chinese culture encourages people to pursue the "ideal personality". It was believed that in the process of pursuing, and upon attainment of the ideal personality, people would be in possession of the kind of happiness and subjective well-being that is achieved through kindness and contribution to society: having intelligence as water, morality as mountains and appreciating and enjoying the beauty of nature (mountain, river and sea). It was thought that when people truly developed the ability to appreciate the wonders of nature and life, the process of this appreciation would become a kind of happiness in itself. Chinese traditional culture forms the characteristics of Chinese, and the basic 
understanding of well-being. With the development of China, well-being is both static and dynamic. Traditional views form the relatively static understanding. But from another angle, the times we lived may somehow change or create a new view or idea for understanding well-being, especially the folk well-being in China should be explored in future.

\section{References}

[1] Gilman, R., Huebner, E.S., Tian, L., Park, N., O’Byrne, J., Schiff, M. and Langknecht, H. (2007) Cross-National Adolescent Multidimensional Life Satisfaction Reports: Analyses of Mean Scores and Response Style Differences. Journal of Youth and Adolescence, 37, 142-154. https://doi.org/10.1007/s10964-007-9172-8

[2] Lu, L. (2007) The Opinion of Happiness and Subject of Well-Being of Chinese. Discovery of Applied Psychology, 9, 19-30.

[3] Waterman, A.S. (1993) Two Conceptions of Happisness: Contrasts of Personal Expressiveness (Eudaimonia) and Hedonic Enjoyment. Journal of Personality and Social Psychology, 64, 678-691. https://doi.org/10.1037/0022-3514.64.4.678

[4] Zeng, H. and Guo, S.P. (2012) "Le": The Chinese Subject Well-Being and the View of Happiness in China Tradition Culture. Acta Psychologica Sinica, 44, 986-994. https://doi.org/10.3724/SP.J.1041.2012.00986

[5] Li, H.M. and Li, H.Z. (2008) "Le" in Chinese Tradition Culture and the Happiness of Life. Chuanshan Journal, 69, 103-105.

[6] Huo, Y.Q., Chen, Y.Y. and Guo, Z.Y. (2013) An Exploration on the Inter Complementary Optimistic Psychological Thoughts of the Confucianism and Taoism in the Traditional Chinese Culture. Acta Psychologica Sinica, 45, 1305-1312. https://doi.org/10.3724/SP.J.1041.2013.01305

[7] Li, Z.H. (1994) The Path of Beauty: A Study of Chinese Aesthetics. Oxford University Press, Oxford, p. 244.

[8] Li, Z.H. (2005) The Practicality Rationality and Happy Culture. SDX Joint Publishing Company, Beijing, p. 217.

[9] Pan, X.Y. (2006) The Exceed the Earthborn Happiness in Daoreligion. The Religion Research, 4, 36-40.

[10] Chen, R.P. (2016) The Aesthetic Realm of Confucius under the Pleasure Cultural.

[11] Chi, Y.C. (2012) Confucianism-A Modern Interpretation 2012 Edition. World Scientific Publishing Co. Pte. Ltd. 5 Toh Tuck Link, Singapore, 212-213.

[12] Gao, L., Zheng, X. and Yan, B.B. (2010) The Differences of Well-Being between the East and the West: From the View of Self-Construal. Advances in Psychological Science, 18, 1041-1045.

[13] Tatarkiewicz, W. (1980) Creativity: History of the Concept. In: A History of Six Ideas, Springer, 244-265. https://doi.org/10.1007/978-94-009-8805-7_9

[14] Ryff, C.D. and Singer, B.H. (2008) Know Thyself and Become What You Are a Eudaimonic Approach to Psychological Well-Being. Journal of Happiness Studies, 9, 13-39. https://doi.org/10.1007/s10902-006-9019-0

[15] Deci, E.L., Koestner, R. and Ryan, R.M. (1999) A Meta-Analytic Review of Experiments Examining the Effects of Extrinsic Rewards on Intrinsic Motivation. Psychological Bulletin, 125, 627-668. https://doi.org/10.1037/0033-2909.125.6.627 